\title{
Análise dos ativos intangíveis de um laboratório público
}

Analysis of intangible assets in a public laboratory

\author{
Elaine Dias ${ }^{1}$ \\ Valéria Macedo ${ }^{2}$ \\ Marcos Cavalcanti ${ }^{3}$
}

\begin{abstract}
Resumo: O presente estudo como objetivo analisar os ativos intangíveis de um laboratório público. Sendo utilizado o método de pesquisa quali-qualitativa e adotando-se o estudo de caso como estratégia de pesquisa. Os dados foram coletados através de um questionário aplicado aos C-level e gerentes. O estudo de caso foi utilizado com a intenção de verificar se as informações e dados obtidos através de relatórios institucionais contribuem para a compreensão dos resultados alcançados com a survey, fazendo uma análise comparativa dos dados. Este estudo trouxe reflexões às discussões sobre ativos intangíveis, como podem ser identificados e de que forma podem contribuir para a gestão do conhecimento, adicionando valor ao negócio em um laboratório público.

Palavras-Chave: Gestão do conhecimento; Ativos intangíveis; laboratório público.
\end{abstract}

\begin{abstract}
The present study aims to analyze the intangible assets of a public laboratory. Using the qualitative research method and adopting the case study as a research strategy. Data were collected through a questionnaire applied to level $C$ and managers. The case study was used with the intention of verifying whether the information and data obtained through institutional reports contribute to the understanding of the results achieved with a research, making a comparative analysis of the data. This study brought reflections to the discussions about intangible assets: how it can be detected and how it can contribute to knowledge management, adding value to the business in a public laboratory.

Key words: Knowledge management; Intangible assets; public laboratory.
\end{abstract}

\section{INTRODUÇÃO}

O avanço de uma economia cada vez mais baseada na organização do conhecimento tem provocado mudanças significativas no mundo dos negócios ( $\mathrm{CHOO}$, 2003). Na sociedade do conhecimento, os capitais intangíveis são a fonte de vantagem competitiva sustentável para as empresas, proporcionando mais produtividade e inovação.

Conforme CORRADO et al (2005), o investimento das empresas em ativos intangíveis tem sido cada vez mais representativo do que em ativos tangíveis. Os intangíveis são representados, por exemplo, pelas marcas valiosas das empresas inovadoras, pelo mercado de patentes e pesquisa e desenvolvimento (P\&D), pelos novos

\footnotetext{
${ }^{1}$ Doutoranda em Ciência da Informação - IBICT/UFRJ. Rio de Janeiro/Brasil. E-mail: elainecfdias@gmail.com

2 Doutorado em Ciência da Informação - IBICT/UFRJ. Rio de Janeiro/Brasil. E-mail: valeriamacademico@gmail.com

${ }^{3}$ Doutorado em Informática - Paris XI - Paris/França. E-mail: marcos@crie.coppe.br
} 
modelos de negócio que utilizam da tecnologia para suportar as tendências da digitalização nos vários processos produtivos.

A definição mais intuitiva de ativos intangíveis nas empresas é um conjunto de ativos não monetários, identificáveis e que não consegue se mensurar pelos meios habituais. Possuir ativos intangíveis com alto valor agregado faz diferença perante a concorrência, tendo o potencial de aumentar sua competitividade e influir no seu desempenho e posição no mercado.

As mudanças que estão ocorrendo no cenário mundial, impactando tanto organizações públicas quanto privadas, em especial nesta Era da Informação e Conhecimento, potencializam o ativo intangível como fonte de vantagem competitiva nas empresas. "Os intangíveis são, assim, o fermento que faz uma organização crescer e criar valor, mas para isso eles têm de ser duráveis e efetivamente internalizados e/ou apropriados pelas organizações". (CAVALCANTI, 2007, p. 11).

A materialização do conhecimento torna-o universal e acessível, tornando-se um patrimônio da empresa e sendo compartilhado por todos que fazem parte do processo. A internalização e aplicabilidade do conhecimento gera valor que transforma conhecimento em recurso estratégico e em subsídio necessário na tomada de decisões.

Nessa perspectiva, considerando o desafio enfrentado pelas empresas na identificação e utilização dos seus ativos intangíveis, este estudo tem como objetivo verificar a percepção dos funcionários de um laboratório público a respeito dos ativos intangíveis com base nos indicadores utilizados para a avaliação dos ativos intangíveis propostos por DEUTSCHER (2008).

\section{CAPITAL INTANGÍVEL}

Etimologicamente originado do latim intangibilis, a palavra intangível significa que algo não pode ser tocado, contrapondo a algo tangível, isto é, palpável e material. As diversas áreas do saber apropriam-se de diferentes abordagens para caracterizar o intangível. O mais usual é caracterizá-lo como um bem (ativo), produtos e/ou serviços, que detêm poder econômico devido ao capital investido neste ativo tornando-o importante para o desempenho e agregação de valor aos negócios das organizações. Dessa forma, há vários contextos de uso do intangível pelas diversas áreas da organização.

Nas áreas de marketing e vendas, o intangível refere-se a um produto ou serviço representado por um ativo ou uma ideia que atende as necessidades do consumidor. Segundo Levitt (1981), a dificuldade em testar e inspecionar os produtos intangíveis como por exemplo, viagem, seguro, conserto, consultoria e softwares torna estes produtos e serviços demandantes da aprovação do consumidor quanto ao seu potencial no mercado. $\mathrm{O}$ autor defende que as empresas que vendem produtos intangíveis invariavelmente oferecem características intangíveis como, por exemplo, o conforto na compra de um carro de passeio ou a qualidade da foto na captura do momento e memória em uma máquina fotográfica ou celular.

Revista Inteligência Empresarial - ISSN: 1517-3860 - V. 42, N. 1, jul. 2020

http://www.crie.ufri.br DOI 10.36559/DPYG5772 
Conclui-se que o intangível para o marketing e vendas é o valor criado ao consumidor por meio de um benefício emocional e de satisfação abstrata, como a qualidade do serviço agregando valor à marca devido o atendimento prestado ao consumidor pela empresa. A reputação da empresa com a materialização da marca tangibiliza este valor.

Segundo o Pronunciamento Técnico do Comitê de Pronunciamentos Contábeis CPC-04, intangível trata-se de um ativo não monetário identificável sem substância física ou o ágio pago por expectativa de rentabilidade futura (goodwill), usualmente conceituado como valor de mercado pelas áreas financeira e contábil. Para Santiago (2007), os objetivos da contabilidade são captar e reconhecer contabilmente os elementos subjetivos referentes à propriedade intelectual, as tecnologias utilizadas entre outros fatores que impactam o valor da empresa, destacando elementos do passado. $\mathrm{Na}$ literatura contábil brasileira e perante órgãos normatizadores goodwill significa "um ativo intangível, que surge nas entidades pela sinergia entre todos os ativos da empresa, registrados contabilmente ou não, e outros aspectos (como a gestão, a força de vendas, a capacidade de distribuição, localização, fidelidade da clientela etc.), que promovem retornos acima do considerado normal (expectativa de rentabilidade futura acima do normal) ". (IUDícIBUS et al, 2010, p. 8). É a cotação do preço da ação que demonstra, ou melhor, mensura o valor percebido valorando os bens intangíveis da empresa, refletido pela expectativa dos seus stakeholders em relação ao seu valor de mercado, representado pelo goodwill.

Segundo os economistas o conceito de intangível refere-se às ideias, ao conhecimento e as relações sociais que através de $P \& D$ e inovação as organizações incorporam e criam valor para sociedade, promovendo o crescimento econômico. Haskel e Westlake (2018) destacam a relevância do investimento em intangíveis nas áreas de $P \& D$, design, marca, logística, estrutura interna e capital humano capacitado e treinado. A existência de ativos intangíveis demanda desenvolvimento de produtos ou processos específicos; investimento em capacidades organizacionais, criação ou fortalecimento de uma plataforma de produtos posicionando a empresa corretamente no mercado competitivo (HULTEN, 2010).

Identificar uma classificação padronizada para os ativos intangíveis é uma tarefa árdua devido um grande número de sugestões de categorias e grupos distintos na literatura e que surgiram nos anos 90 tendo foco principal o capital intelectual. Levantamento realizado na produção acadêmica sobre capital intelectual por Gallon et al (2008) nos Anais do EnAnpad e do Congresso USP, considerados os principais congressos na área da administração, no período de 2000 a 2006, demonstrou que no Brasil o principal modelo citado foi de Edvinsson e Malone (1998), seguido de Sveiby (1997), Stewart (1998), Brooking (1996), sendo que a maioria das recomendações dos autores foi da necessidade da criação de novos modelos de avaliação de capital intelectual. 
Brooking (1996) classificou os intangíveis por meio do capital intelectual e concebeu quatro grupos de ativos: (1) ativos de mercado para medir o potencial da empresa e seus intangíveis relacionados ao mercado: marca, relacionamento com o cliente, fidelidade dos clientes e canais de distribuição, (2) ativos humanos referente a expertise, criatividade e conhecimento dos indivíduos devido a sua capacidade de solucionar problemas de forma dinâmica e coletiva, (3) ativos da propriedade intelectual devido a inovação e a sua demanda pela proteção legal como copyrights, patentes, designs, segredos industriais e know how, e (4) ativos de infraestrutura representados pela adoção de tecnologias, métodos e processos desenvolvidos e utilizados pela cultura organizacional, sistemas de informação, gestão de riscos e banco de dados de clientes.

Edvinsson e Malone (1998), por sua vez, defende que o valor de mercado é resultante do patrimônio líquido contábil e do capital intelectual. O capital intelectual agrupa dois indicadores referente aos ativos intangíveis: (1) capital humano referenciando a combinação de conhecimentos, capacidades de inovação e de desenvolvimento das atividades acrescido da cultura organizacional e (2) capital estrutural caracterizando a estrutura organizacional e as relações com o cliente por meio da marca e tecnologias desenvolvidas pela organização.

Foi Sveiby (1998) quem adotou a nomenclatura de ativos intangíveis para capital intelectual e introduziu a necessidade de avaliar perspectivas de crescimento, renovação, eficiência e estabilidade ou risco para a avaliação desses ativos. A metodologia desenvolvida por Sveiby (1998) Intangible Assets Monitor tornou-se o modelo preferido para estudos que referenciam valor de mercado construído mediante a avaliação de ativos intangíveis (por meio de indicadores de estrutura externa, estrutura interna e competências individuais) e de indicadores de valor contábil dos ativos tangíveis. Concluise que os modelos de mensuração de SVEIBY (1998) e EDVINSSON (1998) foram os primeiros a classificar os ativos intangíveis em categorias, em capitais como estrutural, financeiro e humano.

Cavalcanti, Gomes e Pereira (2001) incorporaram o capital ambiental aos três capitais de referência para análise dos capitais do conhecimento: relacionamento, estrutural e humano. $\mathrm{E}$, ainda defenderam que o os capitais são inter-relacionados sendo necessário uma análise conjunta para a avaliação dos ativos intangíveis existentes na organização. Ainda segundo os autores, o capital de relacionamento tornou-se um capital relevante para avaliar o impacto direto do sucesso do negócio, pois refere-se ao ecossistema de agentes como clientes e fornecedores que influenciam no desempenho da empresa. Já o capital ambiental leva em conta os fatores externos que determinam e limitam a atuação da empresa e sua interação com o mercado, o governo e a sociedade de forma geral. 


\subsection{O Modelo de Avaliação de Ativos Intangíveis de Deutscher (2008)}

A motivação de Deutscher (2008) em repensar os modelos existentes na literatura para a avaliação de ativos intangíveis foi motivada pela necessidade de financiadores, como por exemplo, bancos de desenvolvimento como BNDES adotarem um instrumento analítico de métricas e relatórios para a tomada de decisão na aprovação ou não de investimentos em empresas que surgiram na economia do conhecimento e que tinham como principal característica serem intensivas em intangível. Deutscher (2008) concebeu uma ferramenta que "permite aos financiadores, investidores e demais partes interessadas (stakeholders) conhecer o posicionamento competitivo da empresa face ao mercado ao mesmo tempo em que permite as empresas, estabelecer seus planos de ação para a construção ou aquisição de recursos intangíveis." (Deutscher, 2008, p. 36)

Por meio de seis capitais intangíveis - Estratégico, Ambiental, Estrutural, Relacionamento, Humano e Financeiro - o modelo foi concebido por Deutscher (2008). A figura a seguir representa este modelo.

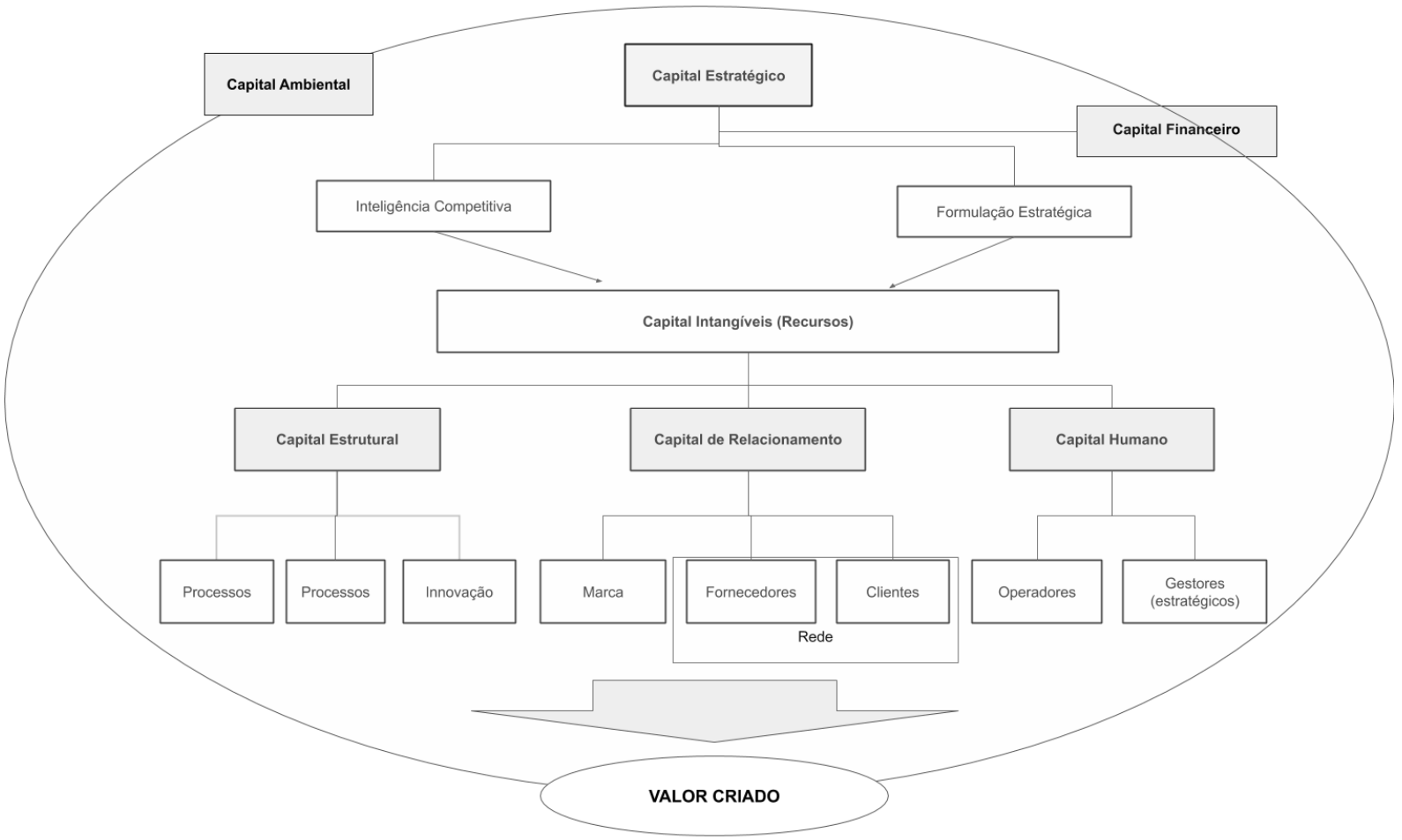

Figura 1 - Os seis capitais intangíveis

Fonte: Deutscher (2010, p. 37)

Deutscher (2010) construiu a ferramenta de análise do rating em conjunto com a equipe do BNDES das áreas de Risco e Mercado de Capitais. Foi adotado na metodologia pesos diferenciados para os capitais levando-se em consideração pequenas e grandes empresas. $E$, ainda, para cada um dos capitais foram elaboradas uma série de perguntas agrupadas em tópicos conforme tabela destacada a seguir: 


\begin{tabular}{|c|c|c|}
\hline Capitais & Ativos & Pesos \\
\hline \multirow[t]{2}{*}{ 1. Estratégico } & 1.1 Competência em monitorar o mercado & $50 \%$ \\
\hline & 1.2 Competência em formular, implementar e acompanhar a estratégia & $50 \%$ \\
\hline \multirow[t]{4}{*}{ 2. Ambiental } & 2.1 Sistema de Financiamento & $30 \%$ \\
\hline & 2.2 Ambiente Regulatório & $20 \%$ \\
\hline & 2.4 Ambiente de Inovação (P\&D) e Empreendedorismo & $20 \%$ \\
\hline & 2.3 Infraestrutura e Logística & $20 \%$ \\
\hline \multirow[t]{5}{*}{ 3. Relacionamento } & 3.1 Carteira de Clientes/ Contratos & $20 \%$ \\
\hline & 3.2 Fornecedores & $20 \%$ \\
\hline & 3.3 Marca - Reputação & $20 \%$ \\
\hline & 3.4 Inserção no Mercado & $20 \%$ \\
\hline & 3.5 Rede - Fornecedores e Clientes & $20 \%$ \\
\hline \multirow[t]{3}{*}{ 4. Estrutural } & 4.1 Sistema de Governança Corporativa & $30 \%$ \\
\hline & 4.2 Processos & $35 \%$ \\
\hline & 4.3 Capacidade de Inovação & $35 \%$ \\
\hline \multirow[t]{2}{*}{ 5. Humano } & 5.1 Gestores & $50 \%$ \\
\hline & 5.2 Operadores & $50 \%$ \\
\hline \multirow[t]{3}{*}{ 6. Financeiro } & 6.1 Confiabilidade & $30 \%$ \\
\hline & 6.2 Administração Estratégica de Risco & $35 \%$ \\
\hline & 6.3 Inteligência Financeira & $35 \%$ \\
\hline
\end{tabular}

Tabela 1: Capitais e pesos

Fonte: Deutscher (2010, p. 43) 
O questionário concebido para a avaliação foi aplicado no formato presencial com entrevistas aos líderes da empresa e mediante pontuação em uma escala Likert de 1 a 7 pontos, onde o avaliador definia as notas para a concepção de uma nota ponderada para cada uma das perguntas. O resultado final apresentou um rating para cada um dos capitais possibilitando a análise dos intangíveis e suas potencialidades nas organizações pesquisadas na tese.

\section{ESTUDO DE CASO}

A produção de medicamentos ocupa um lugar central no processo de acumulação de capital internacional, sendo um dos ramos industriais mais lucrativos (SCHWEITZER, 2007). O setor é historicamente oligopolizado e as grandes indústrias farmacêuticas mundiais têm sede em poucos países - Estados Unidos, Alemanha, Suíça, França e Reino Unido - , onde ocorrem os principais processos de investimento em $P \& D$, vitais para 0 setor provocando concentração de mercado (ACHILLADELIS; ANTONAKIS, 2001).

A indústria farmacêutica é um exemplo de uma indústria intensiva em conhecimento (science-based), onde a inovação é largamente determinada por avanços conjuntos das ciências básicas e aplicadas, associados a progressos complementares nas tecnologias de pesquisa, conduzidas tanto por instituições públicas quanto privadas (BOTTAZZl et al, 2001).

Devido o envolvimento de uma variedade de atores (instituições de pesquisa, firmas, autoridades reguladoras e consumidor/cidadão) na atividade de inovação, a indústria farmacêutica pode ser considerada um sistema (ou rede) pujante e interligada.

No Brasil, o mercado farmacêutico teve um período de auge nos últimos dez anos, com crescimento médio acima de dois dígitos. Nesse contexto, o mercado brasileiro atingiu R\$ 62 bilhões em 2015, o sétimo maior mercado mundial. Mesmo com perspectivas negativas para a economia brasileira, as principais consultorias internacionais ainda estimam crescimento de 7,9\% a.a. entre 2015 e 2020 para o segmento (INTERFARMA, 2016).

Uma das ações estratégicas do governo brasileiro é o fomento à produção pública de medicamentos, a fim de diminuir a dependência do país de tecnologia e insumos importados e a demanda crescente dos medicamentos pela população brasileira no Sistema Único de Saúde (SUS). Os produtores nacionais conhecidos como Laboratórios Farmacêuticos públicos, agem tanto na produção de medicamentos, como em ações estratégicas como indutores de políticas, desenvolvimento de formulações e novos fármacos e, ainda, como regulador de preços no mercado nacional.

O caso selecionado para avaliação dos ativos intangíveis é um laboratório público farmacêutico que investe em pesquisa e desenvolvimento tecnológico na área da saúde para a produção de medicamentos. O objetivo do estudo foi identificar os diferentes pontos de vista do público alvo sobre ativos intangíveis. Como os C-Level (alta 
administração) e gerentes avaliam os capitais intangíveis na organização? Existe relação explícita entre o conhecimento dos capitais pelo público alvo e as informações institucionais divulgadas pela organização aos clientes internos e externos nos canais da intranet e site da organização?

Optou-se, no presente estudo, defini-lo como estudo de caso, porque a pesquisa "investiga o fenômeno contemporâneo dentro de seu contexto da vida real, especialmente quando os limites entre o fenômeno e o contexto não estão claramente definidos" (YIN, 2005, p. 32). O estudo de caso abrange a lógica de planejamento da pesquisa, técnicas de coleta de dados e abordagens específicas de análise dos mesmos. Podem ser incluídas evidências quantitativas e qualitativas, e ficar limitados a uma ou outra, e não exige controle sobre eventos comportamentais.

A metodologia utilizada é de natureza quali-quantitativa, caracterizada como descritiva exploratória. O público-alvo é composto pelas diretoria, vice-diretorias e gerências de um laboratório farmacêutico público.

\subsection{Preparação, elaboração e aplicação do instrumento de pesquisa}

$\mathrm{Na}$ etapa inicial da pesquisa foi a realizada a revisão bibliográfica sobre o tema na literatura. Nesta fase de exploração buscou-se subsídios para a elaboração dos instrumentos de coleta de dados com base no modelo de avaliação de intangíveis de Deutscher (2008). Após análise detalhada do questionário utilizado no modelo de avaliação verificou-se as seguintes oportunidades de melhoria nos processos de preparação, elaboração e aplicação do instrumento de pesquisa.

a. Adequação do questionário mediante o perfil da empresa pública - capital fechado e incorporação de perguntas devido a necessidade de atualização dos fatores que destacam o fenômeno das plataformas de negócio e da formação de redes.

b. As perguntas foram transformadas em questões afirmativas e organizadas em seis grandes blocos: (1) capital estratégico; (2) capital relacional; (3) capital estrutural; (4) capital financeiro (5) capital ambiental e (6) capital humano. O objetivo foi obter respostas diretas para promover uma análise quantitativa do resultado ao invés de promover entrevistas individualizadas flexibilizando a metodologia utilizada por Deutscher (2008).

c. Foi utilizada a escala do tipo Likert para as respostas sendo atribuído em cada item um peso a cada nível de concordância definido pelo respondente que variava de 1 (discordo totalmente) até nível 5 (concordo totalmente). Esse tipo de formato foi adotado por conter pontos positivos já estudados e demonstrados na literatura como ter ponto neutro (decorrente das escalas ímpares) que deixa o respondente mais à vontade no momento de expressar sua opinião como afirma Coelho e Esteves (2007); quanto ao nível de confiabilidade e por se ajustar aos respondentes com diferentes níveis de habilidade. 
d. O instrumento utilizado para a coleta foi o Google Form por possuir características que atenderam as necessidades do questionário como ferramenta gratuita e de fácil acesso, agilidade e eficiência na coleta de informações e garantia de privacidade e sigilo dos respondentes.

O modelo adotado foi composto por três blocos: (1) perfil do respondente (sexo, cargo, tempo de atividade na empresa e grau de escolaridade), (2) 35 questões afirmativas sobre os capitais intangíveis e (3) uma pergunta aberta para o respondente expressar sugestão e/ou colaboração para a pesquisa realizada. Foi realizado um préteste inicial do questionário que resultou na inclusão da pergunta aberta e melhoria no vocabulário utilizado.

\section{APRESENTAÇÃO DOS DADOS E ANÁLISE DOS RESULTADOS}

O questionário foi aplicado durante o mês de junho de 2019 e encaminhados para 47 funcionários. Por meio do software Excel os dados foram tratados e analisados. No total, $62 \%$ responderam à pesquisa (equivalente a 29 funcionários), sendo $55 \%$ homens e 45\% mulheres. Estes respondentes ocupam os seguintes cargos: cinco (5) nível da diretoria; dezenove (19) nível gerencial e cinco (5) nível técnico das áreas estratégica e de inovação, correspondendo $71 \%$ da amostra da diretoria, $58 \%$ do nível gerencial e $70 \%$ dos técnicos.

Em relação ao perfil da formação acadêmica observou-se que os respondentes possuem graduação (10,3\%), pós-graduação (mestrado ou doutorado) (78,9\%) e pósdoutorado (10,8\%). Quanto ao tempo de trabalho na empresa verificou-se que $55,2 \%$ atuam há 10 anos; 34,5\% atuam entre 6 a 10 anos e apenas 10,3\% atuam há menos de 5 anos.

A análise de cada ativo intangível foi agrupada em Capitais nas seis dimensões: estratégico, ambiental, relacional, estrutural, financeiro e humano, seguindo o procedimento de cálculo adotado pelo Modelo de Avaliação de Intangíveis de Deutscher (2010). Observa-se o resultado geral do rating de cada capital no gráfico 1. 


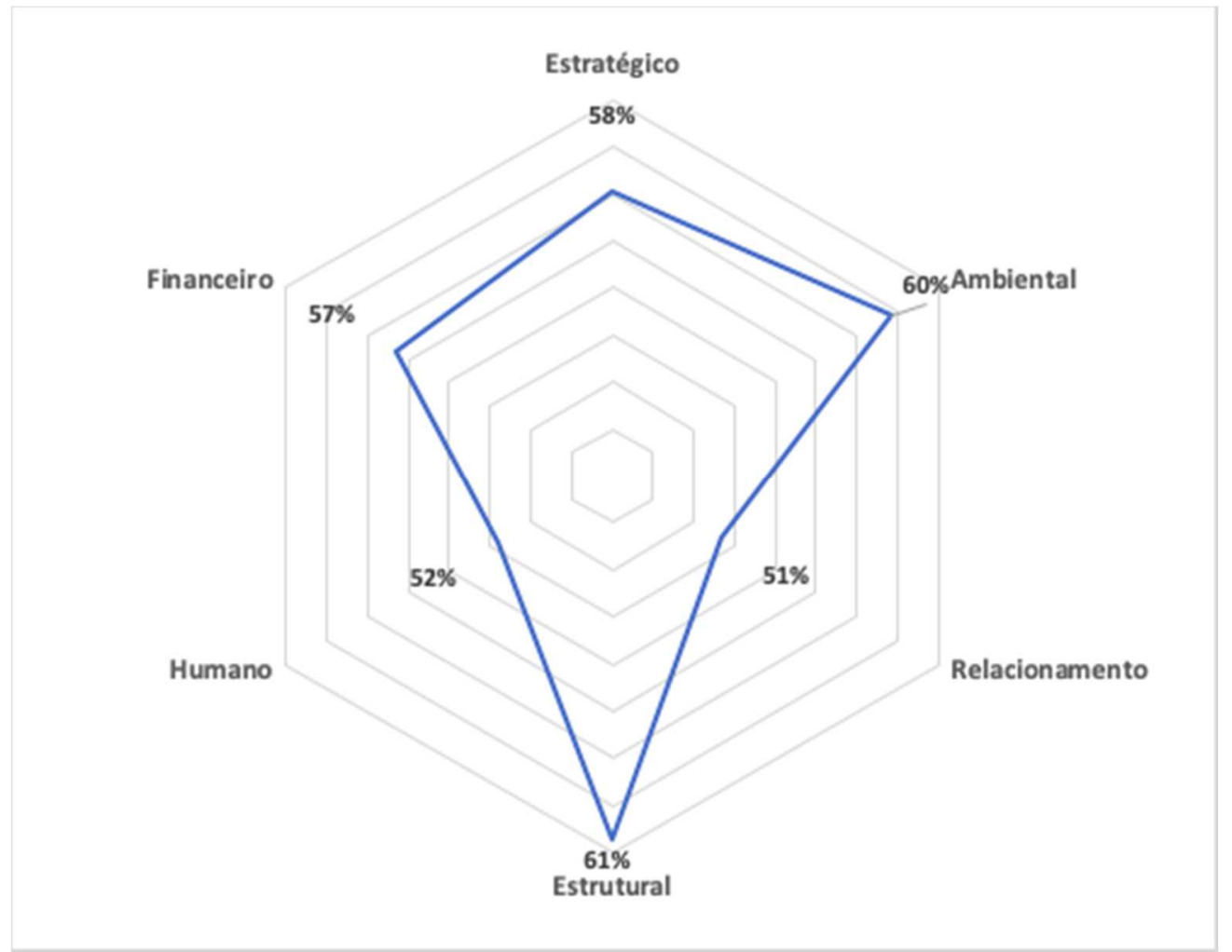

Gráfico 1 - Resultado do Rating por Capital

Fonte: elaborado pelos autores

Em uma escala de $0 \%$ a $100 \%$, o resultado apresenta que os capitais que obtiveram melhor rating foram o Capital Estrutural (61\%) e Capital Ambiental (60\%), seguido do Capital Estratégico (58\%) e Capital Financeiro (57\%). Considerada uma empresa posicionada como organização do conhecimento, verifica-se que os Capitais Humano (52\%) e de Relacionamento (51\%) não foram percebidos pelos respondentes como capitais de relevância quanto ao mundo dos intangíveis. A tabela 2 destaca os ratings obtidos para cada um dos indicadores que compõem cada capital utilizados na pesquisa para a avaliação dos intangíveis.

\begin{tabular}{|l|c|c|c|}
\hline & $\begin{array}{c}\text { Nota } \\
\text { Ponderada }\end{array}$ & $\begin{array}{c}\text { Nota Máxima } \\
\text { Possível }\end{array}$ & Rating \\
\hline $\begin{array}{l}\text { Transparência das informações para o mercado } \\
\text { (peso 10\%) }\end{array}$ & 0,059 & 0,125 & $47 \%$ \\
\hline $\begin{array}{l}\text { Fortalecimento da governança corporativa (peso } \\
10 \%)\end{array}$ & 0,078 & 0,125 & $62 \%$ \\
\hline Responsabilidade Social (peso 15\%) & 0,149 & 0,188 & $79 \%$ \\
\hline Profissionalização da Gestão (peso 10\%) & 0,065 & 0,125 & $52 \%$ \\
\hline
\end{tabular}




\begin{tabular}{|l|c|c|c|}
\hline Responsabilidade Ambiental (peso 15\%) & 0,131 & 0,188 & $70 \%$ \\
\hline Gestão de Projetos (peso 10\%) & 0,071 & 0,125 & $57 \%$ \\
\hline Gestão de Processos de Inovação (peso 15\%) & 0,105 & 0,188 & $56 \%$ \\
\hline Capacidade de P\&D (peso 15\%) & 0,111 & 0,188 & $59 \%$ \\
\hline Total & $\mathbf{0 , 7 6 7}$ & $\mathbf{1 , 2 5 0}$ & $\mathbf{6 1 \%}$ \\
\hline
\end{tabular}

Tabela 2 - Capital Estrutural - Resultados obtidos e Rating Fonte: elaborado pelos autores

Mesmo sendo um dos capitais com melhor avaliação, as respostas demonstraram que os indicadores do Capital Estrutural possuem discrepâncias. A mais evidente é o alto rating dos indicadores responsabilidade social (79\%) e responsabilidade ambiental (70\%) enquanto a transparência das informações para o mercado indicou um rating de $47 \%$.

Quanto ao sistema de delegação de responsabilidades, nos documentos institucionais foram evidenciadas fragilidades na delegação de responsabilidades e na estrutura de liderança, compatível com o resultado baixo no que tange ao indicador profissionalização da gestão (52\%). Outros pontos destacados nos documentos institucionais referem-se à "fragilidade da estrutura de governança"; "baixo aproveitamento das competências relativas à propriedade intelectual e industrial, desperdiçando potencial competitivo" e "fragilidade no portfólio de P\&D", o que vem a corroborar com o resultado apresentado na survey, na percepção dos respondentes com indicadores obtendo rating abaixo de $60 \%$ na gestão de processos de inovação (56\%) e capacidade de P\&D (59\%).

No sentido da avaliação da transparência de informação, não foi possível localizar registros conclusivos a respeito na documentação analisada. Porém, há evidência nos documentos institucionais quanto à "precariedade dos fluxos e sistema de informação para a gestão organizacional e operação", compatível com o encontrado na survey.

No Capital Ambiental (tabela 3), os respondentes avaliaram a empresa quanto ao ambiente no qual atua e se possui ambiente regulatório claro e estável possibilitando investimentos a longo e se está inserida em um setor movido a inovação com parcerias firmadas com instituições de pesquisa, nacionais ou internacionais agregando valor aos produtos e serviços oferecidos.

\begin{tabular}{|l|c|c|c|}
\hline & Nota Ponderada & Nota Máxima Possível & Rating \\
\hline Ambiente regulatório (peso 30\%) & 0,066 & 0,120 & $55 \%$ \\
\hline Ambiente de Inovação (peso 30\%) & 0,094 & 0,150 & $63 \%$ \\
\hline
\end{tabular}




\begin{tabular}{|l|c|c|c|}
\hline Plataforma Logística (peso 20\%) & 0,068 & 0,100 & $68 \%$ \\
\hline Infraestrutura Tecnológica (peso 20\%) & 0,052 & 0,100 & $52 \%$ \\
\hline Total & $\mathbf{0 , 2 8 0}$ & $\mathbf{0 , 4 7 0}$ & $\mathbf{6 0 \%}$ \\
\hline
\end{tabular}

Tabela 3 - Capital Ambiental - Resultados obtidos e Rating

Fonte: elaborado pelos autores

Em relação ao ambiente de inovação nota-se a percepção dos respondentes do valor do ativo intangível obtendo o rating de $63 \%$, maior que a média obtido para o capital ambiental. Esse resultado pode ter sido influenciado pelo grau de investimento em P\&D e estímulo à inovação por meio de parcerias com outras empresas.

Entretanto, o indicador da plataforma logística surpreende obtendo rating de $68 \%$. Confrontando as respostas da pesquisa com a documentação disponível para análise verificou-se que a logística foi avaliada positivamente no diagnóstico interno da empresa, contudo, segundo esse mesmo documento não foi possível atestar informações sobre armazenamento e transporte dentro do prazo, sendo recomendada uma melhor avaliação posteriormente.

Sobre a infraestrutura tecnológica, não foram localizados registros nos documentos consultados para comparabilidade com os resultados deste indicador que obteve o pior rating (52\%).

\begin{tabular}{|l|c|c|c|}
\hline & Nota Ponderada & Nota Máxima Possível & Rating \\
\hline Visão do Ecossistema da Empresa (peso 20\%) & 0,083 & 0,160 & $52 \%$ \\
\hline Compartilhamento da Informação (peso 20\%) & 0,081 & 0,200 & $41 \%$ \\
\hline Planejamento Estratégico (peso 20\%) & 0,108 & 0,160 & $67 \%$ \\
\hline Gestão Estratégica (peso 20\%) & 0,086 & 0,120 & $\mathbf{7 1 \%}$ \\
\hline Elaboração de Plano de Metas (peso 20\%) & 0,108 & 0,160 & $67 \%$ \\
\hline Total & $\mathbf{0 , 4 6 5}$ & $\mathbf{0 , 8 0 0}$ & $\mathbf{5 8 \%}$ \\
\hline
\end{tabular}

Tabela 4 - Capital Estratégico - Resultados obtidos e Rating

Fonte: elaborado pelos autores

$\mathrm{Na}$ percepção dos respondentes verifica-se que o conjunto de práticas relacionadas ao capital estratégico (tabela 4 ) obteve rating médio de $58 \%$ e que o indicador de compartilhamento de informação indicou rating de $41 \%$, bem abaixo da média do capital. Este dado demonstra que os respondentes não reconhecem que as estratégias da empresa neste sentido agregam valor intangível para a empresa e/ou falta 
prática estabelecida de disseminação da estratégia e compartilhamento, buscando o envolvimento dos funcionários.

A mesma percepção pode ser observada no indicador visão do ecossistema da empresa (52\%). Analisando documentos institucionais com o resultado apontado na pesquisa, nota-se que há convergência com o diagnóstico institucional pois foi apontada ausência de mecanismos para o monitoramento do ambiente externo, o que ressalta a necessidade de melhorar o monitoramento e avaliação da estratégia periodicamente e olhar mais atento aos fatores externos.

\begin{tabular}{|l|c|c|c|}
\hline & $\begin{array}{c}\text { Nota } \\
\text { Ponderada }\end{array}$ & $\begin{array}{c}\text { Nota Máxima } \\
\text { Possível }\end{array}$ & Rating \\
\hline Gestão Financeira (peso 20\%) & 0,064 & 0,100 & $64 \%$ \\
\hline Gestão de Riscos Financeiros (peso 20\%) & 0,048 & 0,100 & $48 \%$ \\
\hline $\begin{array}{l}\text { Avaliação Investimentos dos Projetos (peso } \\
\text { 20\%) }\end{array}$ & 0,046 & 0,100 & $46 \%$ \\
\hline Gestão do Fluxo de Caixa (peso 20\%) & 0,071 & 0,100 & $71 \%$ \\
\hline Investimento em P\&D (peso 20\%) & 0,054 & 0,100 & $54 \%$ \\
\hline Total & $\mathbf{0 , 2 8 3}$ & $\mathbf{0 , 5 0 0}$ & $\mathbf{5 7 \%}$ \\
\hline
\end{tabular}

Tabela 5 - Capital Financeiro - Resultados obtidos e Rating Fonte: elaborado pelos autores

No capital financeiro, o resultado ficou em $57 \%$ (tabela 5 ). 0 resultado obtido nos indicadores gestão de fluxo de caixa (71\%) e gestão financeira (64\%) pode ser relacionado ao fato dos respondentes perceberem o uso de sistemas de gestão empresarial (ERP) para gerir seu orçamento. Contudo é relevante o resultado do indicador de gestão de riscos financeiros com rating de $48 \%$ refletindo que a empresa não é reconhecida pela sua capacidade de gerenciar riscos. Nos documentos institucionais foram encontradas ausência de práticas vigentes de formação de receitas e gestão financeira, não proporcionando a sustentabilidade necessária, em concordância com a avaliação dos respondentes. A falta de equilíbrio nos ratings verificados no capital financeiro pode estar relacionada às práticas atuais da gestão dos ativos, o que pode prejudicar a empresa na potencialização dos seus ativos e principalmente, na sua sustentabilidade.

O resultado obtido no Capital Humano (tabela 6), considerado um dos principais ativos intangíveis, demonstra que perante os respondentes a empresa não vem adotando práticas que valorizam este capital. Analisando documentos institucionais no que tange a Força de trabalho, observou-se a inexistência de gestão por competências e ausência de formação contínua de liderança. Em relação ao sistema de desempenho verificou-se na 
documentação institucional oportunidade de melhoria do atual sistema de gestão de desempenho porque "não é possível mensurar, de forma efetiva, os resultados organizacionais, das equipes e indivíduos, diminuindo a capacidade gerencial".

Quanto à gestão do conhecimento buscou-se verificar se há compartilhamento ou transferência desses conhecimentos por parte de seus detentores obtendo-se rating de $58 \%$. Não foi possível identificar na documentação institucional como acontece o compartilhamento e aplicação dos conhecimentos. Consta no documento institucional apenas registro sobre "falta de política de gestão do conhecimento".

\begin{tabular}{|l|c|c|c|}
\hline & Nota Ponderada & Nota Máxima Possível & Rating \\
\hline Qualificação Profissional (peso 20\%) & 0,102 & 0,160 & $64 \%$ \\
\hline Recompensa (peso 20\%) & 0,113 & 0,200 & $57 \%$ \\
\hline Gestão de Competências (peso 20\%) & 0,083 & 0,200 & $41 \%$ \\
\hline Gestão de Desempenho (peso 20\%) & 0,099 & 0,200 & $50 \%$ \\
\hline Gestão do Conhecimento (peso 20\%) & 0,077 & 0,160 & $48 \%$ \\
\hline Total & $\mathbf{0 , 4 7 4}$ & $\mathbf{0 , 9 2 0}$ & $\mathbf{5 2 \%}$ \\
\hline
\end{tabular}

Tabela 6 - Capital Humano - Resultados obtidos e Rating

Fonte: elaborado pelos autores

No Capital Relacional (tabela 7), os respondentes avaliaram a empresa quanto a forma que ela se relaciona interna e externamente. Na visão do seu ecossistema os respondentes já demonstraram a percepção do valor dos ativos intangíveis é consideravelmente baixa (40\%). Nota-se que no Capital Relacional, seus indicadores obtiveram resultados considerados baixos.

\begin{tabular}{|l|c|c|c|}
\hline & Nota Ponderada & Nota Máxima Possível & Rating \\
\hline Feedback & 0,041 & 0,075 & $54 \%$ \\
\hline Grau de Interação & 0,035 & 0,075 & $47 \%$ \\
\hline Gestão de Riscos & 0,050 & 0,090 & $55 \%$ \\
\hline Curadoria & 0,028 & 0,060 & $47 \%$ \\
\hline Reputação & 0,043 & 0,090 & $48 \%$ \\
\hline
\end{tabular}




\begin{tabular}{|l|c|c|c|}
\hline Parcerias & 0,039 & 0,075 & $52 \%$ \\
\hline Fluxo da Informação & 0,049 & 0,090 & $54 \%$ \\
\hline Tecnologia de Informação e Comunicação & 0,057 & 0,113 & $51 \%$ \\
\hline Total & $\mathbf{0 , 3 4 3}$ & $\mathbf{0 , 6 6 8}$ & $\mathbf{5 1 \%}$ \\
\hline
\end{tabular}

Tabela 7 - Capital Relacional - Resultados obtidos e Rating

Fonte: elaborado pelos autores

Nota-se com este resultado o quanto é necessário investir em ações de conscientização dos colaboradores do valor dos intangíveis para a empresa. Analisando a documentação institucional e confrontando com os resultados apontados na pesquisa verifica-se a existência de parcerias estabelecidas, contudo, não foram identificados processos estabelecidos de gestão da rede de relacionamento como curadoria, feedback e grau de interação.

$\mathrm{Na}$ economia do conhecimento é cada vez mais importante criar vínculos, trabalhar em redes com novas formas de se relacionar que os avanços tecnológicos impõem para os atores no ecossistema da empresa, independente se a empresa é pública ou privada.

\section{CONCLUSÃO}

Este estudo trouxe reflexões às discussões sobre ativos intangíveis, como podem ser identificados e de que forma contribuem para a gestão do conhecimento e adicionam valor ao negócio.

A análise dos resultados obtidos permitiu ratificar a aplicabilidade do modelo proposto por DEUSTCHER (2008), com as alterações necessárias para organização pública, no alcance do objetivo proposto e concluir que a análise dos resultados da pesquisa com os documentos institucionais se mostrou efetiva como forma de validação, atribuindo à pesquisa mais profundidade e abrindo perspectivas para continuação do trabalho de análise dos ativos com a Empresa.

Considerando as percepções dos respondentes e as informações obtidas na pesquisa documental quanto à gestão do capital intangível, este estudo identificou os seguintes pontos que podem ser aperfeiçoados no Laboratório: (1) Percepção quanto às fontes de informações e conhecimento dentro da organização, tanto em seus recursos humanos como nas informações contidas nos seus bancos de dados, sistemas e processos; (2) Divulgação e disseminação do conhecimento e informação; (3) Integração da organização à lógica global, onde o fluxo de pessoas, capital e informações será cada vez maior e (4) Maior foco da gestão na estratégia de valor a partir dos ativos intangíveis. 
O estudo se limitou a pesquisar uma instituição pública brasileira voltada para área da saúde, assim, sugestões para pesquisas futuras seriam: (i) aplicação da pesquisa em outras empresas a fim de averiguar a percepção quanto ativos intangíveis; (ii) levantamento de práticas de utilização de indicadores para avaliação de intangíveis em outras empresas.

\section{REFERÊNCIAS BIBLIOGRÁFICAS}

ACHILLADELIS, B.; ANTONAKIS, N. The dynamics of technological innovation: the case of the pharmaceutical industry. Research policy. Brighton, v. 30, n. 4, p. 535-588, Abr. 2001. DOI: 10.1016/S0048-7333(00)00093-7

BOTTAZZI, Giulio, DOSI, Giovanni, LIPPI, Marco, PAMMOLLI, Fabio, RICCABONI, Massimo. Innovation and Corporate Growth in the Evolution of the Drug Industry. 2001. https://doi.org/10.1016/S0167-7187(01)00068-6

BROOKING, A. Intellectual Capital: Core Asset for the Third Millennium Enterprise. Boston. Thomson Publishing Inc, 1996

CAVALCANTI, M. Relatório dos Ativos Intangíveis. Revista Inteligência Empresarial, Rio de Janeiro, E-papers, n. 31, p. 11-15, 2007.

CAVALCANTI, M.; GOMES, E.; PEREIRA, A. Gestão de empresa na sociedade do conhecimento. Rio de Janeiro: Campus, 2001.

COELHO, P.S.; ESTEVES, S.P. The choice between a 5-point and a 10-point scale in the framework of customer satisfaction measurement. Lisboa: ISEGI - Instituto Superior de Estatística e Gestão de Informação, New University of Lisbon, 2007. Disponível em: <https://doi.org/10.1177/147078530704900305 >. Acesso em: 20 de Junho de 2019.

CHOO, C. W. A organização do conhecimento: como as organizações usam a informação para criar significado, construir conhecimento e tomar decisões. São Paulo: Editora Senac, 2003.

CORRADO, C.; HULTEN, C. R.; SICHEL, D. E. Measuring capital in the new economy [Online]. Chicago: University of Chicago Press. 2005. Disponível em http://www. nber.org/chapters/c0202. Acesso em 30 de maio de 2019.

DEUTSCHER, J. A. Capitais Intangíveis - Métricas e Relatório. Tese - Universidade Federal do Rio de Janeiro, COPPE/UFRJ. Rio de Janeiro; 2008. 
Avaliando os capitais intangíveis. Revista Inteligência Empresarial, Rio de Janeiro, E-papers, n. 31, p. 6-10, 2007.

EDVINSSON, L.; MALONE, M. S. Capital intelectual. São Paulo: Makron Books, 1998.

HASKEL, J.; WESTLAKE, S. Capitalism without capital: the rise of the intangible economy. Princeton University Press, 2018.

HULTEN, C. R. Decoding Microsoft: intangible capital as a source of company growth. National Bureau of Economic Research, 2010.

INTERFARMA - ASSOCIAÇÃO DA INDÚSTRIA FARMACÊUTICA DE PESQUISA. Guia Interfarma 2016. São Paulo, 2016.

IUDÍCIBUS, S. et al. Manual de contabilidade societária: aplicável a todas as sociedades: de acordo com as normas internacionais e do CPC, 2010.

LEVITT, T. Marketing intangible products and product intangibles. Cornell Hotel and Restaurant Administration Quarterly, v. 22, n. 2, p. 37-44, 1981.

SANTIAGO, J. R. S. Capital intelectual: o grande desafio das organizações. Novatec Editora, 2007.

SVEIBY, K. E. A Nova riqueza das organizações. Rio de Janeiro: Campus, 1998.

SCHWEITZER, S. O. Pharmaceutical economics and policy. Oxford: Oxford University Press, 2007.

YIN. R. K. Estudo de caso: planejamento e métodos. 3 ed., Porto Alegre: Bookman, 2005. 